\title{
«APUd CADESSE»: PAISAJE MARÍTIMO Y NAVEGACIÓN \\ GENOVESA EN EL PUERTO DE CÁDIZ EN EL SIGLO XIII
}

\section{«APUD CADESSE»: MARITIME LANDSCAPE AND GENOESE SHIPPING IN THE PORT OF CADIZ IN THE $13^{\text {TH }}$ CENTURY}

\author{
DANIEL RÍOS TOLEDANO ${ }^{1}$ \\ daniel.riostoledano@gmail.com
}

UNIVERSIDAD DE CÁDIZ

http://dx.doi.org/10.25267/Riparia sup.2019.i2.04

\section{RESUMEN}

Las investigaciones sobre los puertos andaluces atlánticos han adquirido relevancia a raíz del análisis de la documentación italiana bajomedieval. Estas fuentes documentales están aportando nuevos datos referentes a la navegación y al comercio en los puertos castellanos del sur ibérico. Este estudio pretende arrojar nuevas perspectivas sobre el puerto de Cádiz a finales del siglo XIII a partir del análisis de fuentes archivísticas, aportando datos inéditos sobre el comercio y la navegación genovesa en el litoral gaditano.

Palabras Claves: Cádiz. Génova. Comercio. Navegación. Redes portuarias.

1 Graduado en Historia por la Universidad de Cádiz (2015). Máster en Formación del Profesorado de ESO y Bachillerato por la Universidad de Granada (2017). Máster en Patrimonio, Arqueología e Historia Marítima por la Universidad de Cádiz (2018).

D. Ríos Toledano, «Apud Cadesse»: Paisaje marítimo y navegación genovesa en el puerto de Cádiz en el siglo XIII», Suplemento RIPARIA 2 (2019), 81-111. 


\section{Abstract}

Studies on ports of Atlantic Andalusia have gained traction in recent time following a review of medieval sources from Italy. Those sources are providing new data about navigation and trade on Castilians ports in southern Iberia. This study intends to contribute new perspectives about port of Cadiz at the end of the thirteenth century on the basis of the analysis archival sources, providing unprecedented data about Genoese navigation and trade in the Cadiz coasts.

KEYwORDS: Cadiz. Genoa. Trade. Navigation. Port networks.

«Apud Cadesse»: paisaje marítimo y navegación genovesa en el puerto...» 


\section{Introducción}

El presente artículo pretende abordar el comercio marítimo en el mundo medieval desde la óptica del puerto de Cádiz. En esta ocasión centraremos nuestra atención en el siglo XIII, con la finalidad de profundizar exhaustivamente en el papel desempeñado por la ciudad portuaria gaditana como punto de escala de primer orden para las embarcaciones genovesas que surcaban el Mar Mediterráneo y el Océano Atlántico. El marco cronológico se corresponde con las últimas décadas de este siglo, debido a que en este período se produjo una intensificación del tráfico comercial del área mercantil atlántica, a tenor de la búsqueda de nuevos mercados en Occidente y de la puesta en funcionamiento de la ruta marítima de Poniente.

Las fuentes disponibles para elaborar el presente estudio proceden fundamentalmente de las actas notariales genovesas del siglo XIII que fueron recopiladas en la publicación de Eugene $\mathrm{H}$. Byrne $^{2}$. Este estudio comprende el análisis de cinco protocolos de los notarios ligures: Simone Vattaccio y Angelino de Sigestro. En ellas se recogen dos «naulisatio navis» y tres «accomendacio», los cuales ofrecen datos sumamente sugestivos para profundizar en la organización portuaria de Cádiz dentro de las redes mercantiles de la República de Génova. De hecho, estas fuentes documentales aportan una información realmente provechosa sobre este puerto castellano, tales como: duración de la escala, mercancías exportadas o importadas, tipología de las embarcaciones que fondeaban en su bahía, entre otras cuestiones especialmente.

De un lado, el «naulisatio navis» es un contrato de transporte por mar, o bien el alquiler de la nave, estipulado entre un mercader con un patrón — propietario o capitán— encargado

${ }^{2}$ E. H. Byrne, Genoese shipping in the twelfth and thirteenth centuries, Cambridge 1930. 
de pilotar la embarcación, quien, asimismo, se compromete a disponer de un determinado navío en perfectas condiciones y a transportar una mercancía precisa a un lugar establecido por un precio acordado. En el contrato el patrón especifica la ruta que surcará la nave, si bien no se indica plazos de entrega de las mercancías a su puerto de destino, dada las dificultades inesperadas de la navegación. A su vez, el mercader, dueño de los bienes, se compromete a entregarlos para su respectivo embarque en el lugar y día estipulado, así como a abonar los gastos del transporte, y en el caso de haber alquilado el barco se especifica el puerto en que se produciría su devolución. El precio del flete está formalizado en función del valor de la mercancía ${ }^{3}$.

De otro lado, la «accomendacio» es un contrato en el que una parte fía a otra una determinada cantidad económica para comerciar, con el fin de dividir el beneficio según una proporción convenida. Generalmente, el socio capitalista recibe, una vez finalizado el negocio, la restitución entera del capital más una parte de los beneficios. En el caso concreto de este estudio, el mercader Giovanni Rovegno de Castro había recibido de los hermanos Zaccaria «in accomendactione» trescientas libras genovesas para invertir en alumbre de Focea y, también, su nave «Bonaventura» para comerciar dicha mercancía en Génova, Mallorca y Cádiz, a cambio de recibir la 1/4 de las ganancias, mientras que los hermanos Zaccaria obtendrían la devolución total del dinero invertido más $3 / 4$ del beneficio. En general, el texto de «accomendacio» consiste, fundamentalmente, en una declaración por parte del socio gestor que afirma haber recibido una cierta cantidad de dinero con el compromiso de devolver el capital y una parte de los beneficios. El socio gestor dispone de libertad de movimiento para comercializar la mercancía cargada

\footnotetext{
${ }^{3}$ G. Costamagna, Corso di scritture notarili medievali genovesi, Génova 2017, 91. «Apud Cadesse»: paisaje marítimo y navegación genovesa en el puerto...»
} 
en cualquier lugar, pero en ocasiones se oprimen bajo la fórmula: «vel alibi ubicumque Deus michi melius administraverit» ${ }^{4}$.

\section{Cádiz, «puerto aquende la mar»}

A finales del siglo XIII el dominio marítimo castellano se extendía a lo largo de la costa atlántica andaluza hasta el Estrecho de Gibraltar. Desde de la segunda mitad del citado siglo, la Corona de Castilla hizo patente su control sobre el mar a través de diversos mecanismos políticos y económicos, a tenor de su pretensión por reorganizar la red portuaria que englobaba a los centros de intercambios costeros y fluviales del sur ibérico ${ }^{5}$. De hecho, la propia geopolítica del monarca Alfonso X concedió a los puertos andaluces una notable importancia por dos razones esenciales: de un lado, consolidar rutas comerciales y fomentar la apertura de nuevos mercados castellanos y, de otro lado, establecer bases navales destinadas a promover sus proyectos de expansión y conquista hacia el Norte de África ${ }^{6}$.

${ }^{4}$ G. Costamagna, Corso di scritture notarili..., 89-90. 22-III-1286: E. H. Byrne, Genoese shipping..., doc. XLVI.

5 E. Aznar Vallejo, «Experiencia marítima: las rutas y los hombres del man», A. Collantes de Terán SÁnchez y A. García-Baquero GonzÁlez(Coords.), Andalucía 1492: razones de un protagonismo, Sevilla 1992, 127. J. M. BELLO LEÓN, «El Reino de Sevilla en el comercio exterior castellano (siglos XIV-XV)», H. CASAdo Alonso (Ed.), Castilla y Europa: comercio y mercaderes en los siglos XIV, XV y XVI, Burgos 1995, 57 58. A. Collantes de Terán SÁnchez, «Papel del Atlántico en la configuración de Andalucía», Historia. Instituciones. Documentos, 35, (2008), 87-88. J. F. JimÉnEZ AlCÁZAr, «Castilla y el mar Mediterráneo: encuentros y desencuentros en la Baja Edad Media», Intus-Legere Historia, vol. 5, 2, (2011), 9-10.

${ }^{6}$ M. GONZÁLEZ JimÉNEZ, «La idea y la práctica de la Cruzada en la España medieval: Las Cruzadas de Alfonso X», El Mediterráneo: hechos de relevancia histórico-militar y sus repercusiones en España, Sevilla 1997, 171-186. 
En este marco, Cádiz se convirtió en base logística para la flota castellana, cuyo objetivo era controlar Ceuta, aunque por circunstancias desconocidas, la expedición se desvío hacia Salé?

Desde el puerto de Sevilla partió la armada castellana, bajo el mando del almirante Pedro Martínez de Fe y Juan García, Adelantado de la Mar, destinada a la conquista de Cádiz y su entorno. La propia crónica de Alfonso X señala algunos de los aspectos que más llamaron la atención de la ciudad: «avia muchas mercaderías, é oro é plata é otras cosas de muy grandes prescios» ${ }^{8}$. Efectivamente, una vez incorporada la ciudad gaditana dentro de la órbita castellana, su puerto se instauró como base de la marina de Castilla, como así lo revela el empréstito de 1.200 maravedíes solicitado por el monarca a los concejos de Galicia y Asturias para habilitar a las naves y galeras que se concentrarían en la plaza de Cádiz para desarrollar la empresa del «fecho de allende» ${ }^{9}$. La trascendencia de la ciudad y de su puerto queda también de relieve en la bula «Excelsum fecit in» del papa Urbano IV de agosto de 1263 al indicar que disponía de «un puerto de

7 M. GonZÁLeZ JimÉnEZ, «Cádiz en el siglo XIII: Historia de un Proyecto frustrado», M. GonzÁlez Jiménez y I. Montes Romero-CAmacho (Coords.), La Península Ibérica entre el Mediterráneo y el Atlántico. Siglos XIII-XV, Cádiz-Sevilla 2006, 749.

${ }^{8}$ C. Rosell (Ed.), Crónicas de los reyes de Castilla desde Don Alfonso El Sabio basta los católicos Don Fernando y Doña Isabel, vol. I, Madrid 1875, 13-15. La cita textual en la página 14. El capítulo XIX - De commo el rey don Alfonso ganó á Cáliz, é de commo quitó el tributo á Portogal que daba á Castilla, é de lo que de esto se recresció - relata la conquista de Cádiz. Algunos autores han denunciado la difícil labor de interpretar este suceso dadas las similitudes entre el topónimo de Cádiz y Salé en las fuentes cronísticas. Estamos en lo cierto de creer que se trataba de la conquista de Cádiz y no del saqueo de Salé por varios motivos: el empleo del topónimo «Cáliz» para referirse a Cádiz, así se manifiesta en la documentación cuando aparece el nombre de los obispos gaditanos acompañados del calificativo «obispo de Cáliz», o también en el documento de la cita posterior que indica lo siguiente: «las naves et las galeas commo fossen en Cáliz primer día de mayo». La propia imagen que describe la crónica coincide con las nuevas fuentes disponibles sobre la ciudad en época islámica: D. Ríos TOLEDANO, «En el Atlántico musulmán: rutas, intercambios y saqueos en Cádiz», En prensa.

9 C. Miguel y Vigil, Colección Histórico-Diplomático del Ayuntamiento de Oviedo, Oviedo 1889, doc. XXII, 46.

«Apud Cadesse»: paisaje marítimo y navegación genovesa en el puerto...» 
mar apropiado y tranquilo, está opuesta y, gracias al estrechamiento del mar Mediterráneo muy cerca de África, y puede ser para los fieles una puerta para su conquista» ${ }^{10}$.

Tras la conquista de la ciudad, con el objetivo de consolidar la presencia castellana en el alfoz gaditano, en 1262 el rey Alfonso X ordenó la instalación de cien hombres de armas. Liderados por el catalán Guillem de Berga, recibieron las alquerías almohades de Campix, Grañina, Finojera, Poblanina y Fontanina, ubicadas entre el río Guadalete y el arroyo Salado ${ }^{11}$. De hecho, este primer repartimiento, de un área geográfica concreta del término, no debió resultar factible por dos motivos: el surgimiento de la revuelta mudéjar en 1264 y la concesión del monarca de un nuevo privilegio en marzo de 1266 al concejo de Cádiz, al que beneficiaba con las cinco alquerías que había sido otorgadas al citado Guillem cuatro años antes, promoviéndose un nuevo reparto del alfoz gaditano. La cifra de pobladores se incrementó notablemente de cien a trescientos -doscientos lanceros y cien ballesteros- y se distribuyeron las nuevas alquerías de Casajeros, Villarana, Bayna, Bollullos, MarchalTamarit y Marchal-Grasul, así también las casas y las tierras calvas de Alcanate (Santa María del Puerto) ${ }^{12}$.

A pesar de que la información relativa al repartimiento de la ciudad de Cádiz y su alfoz es escasa, no cabe la menor duda de que debió ser un fenómeno paulatino que abarcó desde 1262 hasta 1268. La desaparición del libro del repartimiento, a raíz del asalto anglo-holandés de 1596, dificulta el conocimiento de este proceso. A pesar de ello, disponemos de algunos datos

${ }^{10}$ L. Charlo Brea y M. B. Piqueras García, «Bulas fundacionales de la Diócesis de Cádiz», Actas do IV Congresso Internacional de Latim Medieval Hispánico, Lisboa 2006, 342.

11 1262: M. GonzÁlez Jiménez (Ed.), Diplomatario Andaluz de Alfonso X, Sevilla 1991, $\mathrm{n}^{\mathrm{o}} 259$.

12 1266, marzo, 30. M. GonZÁlez JimÉnez (Ed.), Diplomatario Andaluz de Alfonso X..., $\mathrm{n}^{\mathrm{o}} 310$. 
transmitidos por el historiador Agustín de Horozco a fines del siglo $\mathrm{XVI}^{13}$ y de una copia del libro del repartimiento del rural de su primitivo alfoz, centrada solamente en las tierras referentes al actual término municipal de El Puerto de Santa María. Manuel González Jiménez ha propuesto las siguientes etapas cronológica de los repartos del alfoz gaditano:

\begin{tabular}{|c|c|l|}
\hline Partición & Año & \multicolumn{1}{c|}{ Repartos } \\
\hline $1^{\mathrm{a}}$ Partición & $1262-1266$ & Las casas y solares de Cádiz \\
\hline $2^{\mathrm{a}}$ Partición & $1262-1266$ & Las tierras de cultivos en las alquerías de La Puente y Rayhana \\
\hline $3^{\mathrm{a}}$ Partición & 1268 & Las viñas de Santa María del Puerto \\
\hline $4^{\mathrm{a}}$ Partición & $1266-1268$ & Las viñas de la alquería de Casarejos \\
\hline $5^{\mathrm{a}}$ Partición & $1266-1268$ & Las tierras calvas de la alquería de Casarejos \\
\hline $6^{\mathrm{a}}$ Partición & $1262-1268$ & Las casas y tierra de labor de la alquería de Casarejos \\
\hline $7^{\mathrm{a}}$ Partición & $1266-1268$ & $\begin{array}{l}\text { Las tierras de las alquerías de Villarana, Bayna, Bollullos, Machar } \\
\text { Tamarit y Machar Grasul }\end{array}$ \\
\hline $8^{\mathrm{a}}$ Partición & 1268 & Las tierras calvas de Santa María del Puerto \\
\hline $9^{\mathrm{a}}$ Partición & $1262-1268$ & $\begin{array}{l}\text { Las tierras de las alquerías de Campix, Grañina, Finojera, } \\
\text { Poblanina y Fontanina }\end{array}$ \\
\hline $10^{\mathrm{a}}$ Partición & 1268 & Las casas de Santa María del Puerto \\
\hline
\end{tabular}

Tabla 1. El repartimiento de Cádiæ. ${ }^{14}$

Un análisis comparativo entre los datos aportados por Agustín de Horozco y los del repartimiento rural gaditano manifiesta diferencias entre ambos. En virtud de la copia del libro, conocemos perfectamente las reparticiones de las diversas alquerías y de las tierras de Santa María del Puerto, pero desconocemos las dos primeras particiones referentes a la ciudad gaditana y a las alquerías de La Puente y Rayhana. El historiador Agustín de Horozco en su celebérrima obra proporciona una nómina de nombres de los pobladores de Cádiz, concretamente un elenco de 161 personas — cabe recordar que examinó el original del libro del repartimiento de Cádiz antes del incendio de la ciudad, aunque cita que fueron 300 pobladores, pero no los

13 A. De Horozco, Historia de Cádiz, edición, introducción y notas a cargo de A. Morgado García, Cádiz 2001, 55-60.

14 M. GonzÁlez Jiménez (Ed.), Repartimiento de El Puerto de Santa María, Sevilla-El Puerto de Santa María 2002, LXXXIII-LXXXIV.

«Apud Cadesse»: paisaje marítimo y navegación genovesa en el puerto...» 
incluye todos en su lista porque «no se puede leer ni entender»-, de los cuales se puede estimar que entre 50-60\% aparecen también en el repartimiento rural. ¿Y qué ocurre con el resto de las personas que menciona? Posiblemente se tratarían de las gentes que recibieron los solares y las casas de Cádiz, así como las tierras de cultivos de las alquerías de La Puente y Rayhana. Curiosamente entre los cuales figuran algunos pobladores de origen italiano, tales como Domingo Juan de Negrón Domenico Giovanni Negrone-, Domingo Dorno -Domenico Adorno- ${ }^{15}$ o Nicolás Ganzana —Niccolò Genzano-; aunque prevalecen los cántabros y vascos, están igualmente constatados franceses, catalanes y portugueses ${ }^{16}$.

En noviembre de 1268, una vez finalizado el repartimiento, Alfonso X concedió a Cádiz un nuevo privilegio que determinaba la integración de los concejos de Sanlúcar, Rota, Sidueña y La Puente dentro del amplio término gaditano y les autorizaba a nombrar dos alcaldes y un alguacil, aunque debían ser confirmados por el concejo de Cádiz ${ }^{17}$. En efecto, el alfoz gaditano se extendía desde La Puente — abarcando los actuales

\footnotetext{
15 Resulta probable que Domenico Adorno, beneficiario del repartimiento de las casas y tierras gaditanas, fuese el mismo capitán genovés que en 1285 halló la imagen de Nuestra Señora de la Consolación en plena tempestad en el Golfo de Rosas, cuando navegaba rumbo a Cádiz con su escuadra para socorrer a Jerez del sitio de los benimerines. Dicha imagen fue venerada en la primitiva capilla de los Adorno de la iglesia del Convento de Santa Domingo de Jerez de la Frontera. La leyenda en M. Romero Bejarano, «Tres copias en barro desconocidas de Ntra. Sra. de la Consolación en el convento de franciscanas descalzas de San José de Jerez de la Frontera», F. J. CAmpos y Fernández DE SEvilla (Coord.), La clausura femenina en España, Vol. II, 2004, 1053-1055.

16 Para una aproximación al repartimiento gaditano, me remito al estudio clásico de $\mathrm{H}$. SANCHO DE SOPRANIS, «La repoblación y el repartimiento de Cádiz por Alfonso X», Hispania, 15, (1955), 483-539.

17 1268, noviembre, 6. M. GonZÁlez Jiménez (Ed.), Diplomatario Andaluz..., no 353.
}

UNIVERSIDAD DE CÁDIZ 
términos municipales de San Fernando y Chiclana de la Frontera- hasta Sanlúcar de Barrameda ${ }^{18}$.

Entre las pretensiones de Alfonso X estaba la de convertir a Cádiz en un floreciente centro comercial y militar, navegante y eclesiástico. Con el fin de potenciar el despliegue de sus actividades mercantiles le concedió privilegios y exenciones fiscales. En efecto, en marzo de 1263, recibió la autorización para disponer de una feria anual de un mes duración, así como la franquicia de impuestos, en concreto, del portazgo y de la «maltolta» a todos los vecinos y la exención de todos los derechos a los mercaderes que acudieran a su puerto, lo que revela «la voluntad regia de convertir a Cádiz no sólo en una base naval, también en un centro comercial capaz de atraer los intercambios y tráficos a los que tan bien la dispone su posición» ${ }^{19}$.

Como consecuencia de las vicisitudes y contrariedades de la frontera, el término de Cádiz, fue gradualmente perdiendo sus posesiones en tierra firme. En 1297, Fernando IV concedía Sanlúcar y Rota a Alonso Pérez de Guzmán en respuesta por su perseverante participación bélica en la defensa de Tarifa. Por su parte, el Santa María del Puerto, una vez segregada del alfoz

\footnotetext{
18 E. MARTÍN GUTIÉRREZ, «El aprovechamiento de humedales y marismas en el término de Cádiz: segunda mitad del siglo XIII», Qui lacus aquae stagna paludes sunt... Estudios históricos sobre humedales en la Bética, L. G. Lagóstena Barrios (Ed.), Cádiz 2015, 130.

19 R. SÁnchez SAus, «Cádiz y Alfonso X el Sabio. Traslado de la sede asidonense a Cádiz. Repoblación de la ciudad y su término durante su reinado», Traslatio Sedis: catálogo de la exposición conmemorativa del 750 aniversario del traslado de la sede episcopal a Cádir, Granada 2018, 66-102. La cita textual en p. 82. D. Ríos ToledANO, «El puerto de Cádiz en la Baja Edad Media: una introducción a su estudio», En Prensa.
}

«Apud Cadesse»: paisaje marítimo y navegación genovesa en el puerto...» 
gaditano y con su carta-puebla otorgada en $1281,{ }^{20}$ había recibido el término de Sidueña en $1284^{21}$.

A finales del siglo XIII, el alfoz de Cádiz comprendía la ciudad gaditana, el término de La Puente, así como el elenco de aldeas mencionadas en el repartimiento. Bajo la jurisdicción de La Puente quedaron integradas la alquería de Rayhana — concedida a Gonzalo Díaz de Sevilla por Alfonso XI en 1335_,22 y Chiclana —otorgada a Alonso Pérez de Guzmán por Fernando IV en 1307 _ ${ }^{23}$. Sea como fuere, hasta mediados del siglo XIV, las aldeas de Campix, Grañina, Finojera, Poblanina, Fontanina, Casajeros, Villarana, Bayna, Bollullos, Machar Tamarit y Marchar Grasul quedaron incorporadas dentro del término gaditano ${ }^{24}$. Como resultado de ello, el concejo de Cádiz dispuso de posesiones en las tierras del interior de la bahía — su binterland-, de cuya explotación y aprovechamiento adquirió recursos naturales que fueron destinados tanto al abastecimiento de la población como a las actividades comerciales.

20 1281, diciembre, 16. M. GonzÁlez Jiménez (Ed.), Diplomatario Andaluz..., no 487.

21 J. E. Jiménez López de Eguileta, «Las tierras de las Salinas de El Puerto de Santa María, el repartimiento y término de Sidueña y la jurisdicción de Cádiz a finales del siglo XIII», En prensa. Agradezco a su autor la posibilidad de consultar el texto inédito.

22 A. Franco Silva, La Isla de León en la Baja Edad Media, San Fernando 1995, Apéndice documental, p. 75.

23 M. Á. LAdero Quesada y M. GonZÁlez JimÉnEZ, «La población en la frontera de Gibraltar y el repartimiento de Vejer (siglos XIII y XIV)» Historia. Instituciones. Documentos, 4, (1977), 234-235.

${ }^{24} \mathrm{El}$ análisis de nuevos documentos por Javier Jiménez López de Eguileta ha permitido revalorar su extensión geográfica. Ahora sabemos que las aldeas quedaron integradas bajo la órbita de poder del concejo gaditano, tal como queda de manifiesto en dos documentos datados en 1302 y 1313, donde aparecen los topónimos de las alquerías acompañados del calificativo de «aldeas de Cádiz». De tal forma, se pueden desestimar los planteamientos de Manuel González Jiménez que afirmaban que las mencionadas aldeas habían sido incorporadas al dominio de El Puerto de Santa María. J. E. JiméneZ LÓPEZ DE EGUiLETA, «Las tierras de las Salinas..., En prensa. 
En las Cortes de Jerez de 1268 se implantó el primer ordenamiento aduanero de los puertos marítimos de la Corona de Castilla $^{25}$. De esta forma, se pueden conocer cuáles eran los princi-pales ciudades y villas portuarias que destacaban por la condición de ser centros canalizadores del tráfico mercantil del reino castellano. Así pues, el monarca Alfonso X estableció aduanas en los siguientes puertos del sur ibérico: Huelva, Cádiz, Vejer de la Frontera, Sevilla y Jerez de la Frontera. Estableciéndose así que «mas son puestas en las villas do se han ayuntar las mercadorias, e son y puestos los ommes que han a tomar los fiadores de los mercadores» ${ }^{26}$. De este modo, la política de control del comercio exterior quedó reglamentada mediante la configuración de los puntos aduaneros, la prohibición de exportar determinadas mercancías y la imposición de las tasas. Asimismo, las actas de las Cortes de Jerez de 1268 revelan los nombres de los encargados de designar a los fiadores — cuya función era contabilizar «todas las mercadurias que quisieren por y sacar»en la aduana de Cádiz: Diego Pérez, hijo de Pedro de Llano, y Pedro Alfonso, alcalde mayor, quienes además habían obtenido sendas propiedades en el repartimiento gaditano ${ }^{27}$.

25 Para el caso de los puertos marítimos del norte ibérico: J. I. RUIZ DE LA PEÑa SOLAR, «Las villas castellanas de la costa cántabro-atlántica y su proyección comercial en el Mediterráneo occidental», Revista d'historia medieval, 11, 2000, 41-66, 52.

${ }^{26}$ Cortes de los antiguos reinos de León y de Castilla, Madrid 1861, I, 74-75.

27 Por un lado, Diego Pérez de Llano había recibido «media arançada e media quarta de vinnas, e vna arançada de tierra» en las viñas de Santa María del Puerto, «una quarta» en las viñas de Casarejos, «una quarta» en las tierras de Casarejos, «vna cauallería e media» en la alquería de Villarana, «seys cauallerías» en la alquería de Poblanina, «vna arançada» en las tierras calvas de Santa María del Puerto y «vn par de casas» en Santa María del Puerto. Partidas nn. 66, 412, 512, 844, 1155, 1416 y 1728, respectivamente. Por otro lado, Pedro Alfonso había obtenido «media arançada e media quarta de vinnas, e vna arançada de tierra» en las viñas de Santa María del Puerto, «tres arançadas» en las viñas de Casarejos, «tres arançadas» en las tierras de Casarejos, «vna cauallería» y «siete cauallerías» en la alquería de Villarana, «treze cauallerías e media» en la alquería de Campix, «seys cauallerías» en la alquería de Grañina, «la torre con la caseta chica» en Grañiña y «dos arançadas» en las tierras calvas de Santa María del Puerto. Partidas nn.

«Apud Cadesse»: paisaje marítimo y navegación genovesa en el puerto...» 
Tanto los portulanos como las cartas náuticas aportaron a los marineros extranjeros una información sumamente valiosa sobre el conocimiento de la costa, los puertos y los principales accidentes geográficos. En esta misma línea, Lo Compasso de navegare, un portulano anónimo custodiado en un manuscrito datado en enero de 1296, recoge una detallada descripción costera desde el Cabo de San Vicente en Portugal hasta el Estrecho de Dardanelos, proporcionando un elenco de topónimos y datos sugestivos de la costa mediterránea.

El siguiente fragmento describe el territorio comprendido entre el río Guadalquivir y el monte de Gibraltar. El texto detalla una notable cantidad de características de los puertos citados, sobre su calado, su abrigo, incluso se mencionan las instrucciones para poder entrar en ellos, aunque escasas son las noticias referentes a la actividad comercial. Su relevancia no radica solamente en sus precisas indicaciones de hitos peligrosos para la navegación como Salmedina, Trafalgar o las múltiples secas en la desembocadura del Guadalquivir, sino por los interesantes datos sobre los puertos de Sevilla, Cádiz y Algeciras, y sus respectivas distancias con otros centros portuarios como Ceuta, Tarifa o Gibraltar:

Se volete entrare êllo dicto flume de Sibilia con nave, enprimamente scandallia lo fondo, e mecti li segnali, e quando l'acqua entra, o quanno cressci, e tu va per la via de li segnali. La dicta Ermendina fo città che perfondao, e devete onorare la po(n)ta de la dicta Ermendina, quanno l'acqua edè plena entorno j mill(a)r(o).

De la dicta Ermendina all'isola de Cadese à xx mill(a)r(a) per sirocco. Enna dicta isola sì è bono porto che è enco(n)tra de la città deguastata, çoè a ddire ver tramontana, e ffondo entorno

108, 365, 547, 777, 815, 992, 1000, 1175, 1265 y 1434, respectivamente. M. GoNZÁLEZ JimÉnEZ (Ed.), Repartimiento de El Puerto... 
vj passi. E da lo dicto porto entro a la ponta de la dicta enver lo ponemte, çoè a ssavare per canale, à fondo entorno viii passi.

De lo dicto Cadesse entro a Talfagar à xxx mill(a)r(a) per sirocco. Sover lo dicto Talfagar, en mare vij mill(a)r(a) per garbino, à una secca, e podete entrare entre la secca e la terra lo(n)tano de terra entorno j m(i)l(laro) e mecço.

De lo dito Cadesse a Susta e[n]t(r)o lx m(i)l(lara) per sirocco ${ }^{28}$.

Referente al tema de nuestro estudio, interesa especialmente la descripción que hace el portulano sobre la isla y ciudad de Cádiz. La información del portulano de 1296 es indudablemente próspera y pormenoriza la realidad del paisaje portuario gaditano a fines del siglo XIII. De hecho, Cádiz disponía, sobre todo, un «bono porto» estratégicamente situado y con posibilidades favorables para el atraque de naves, pues precisamente contaba con una profundidad que oscilaba entre seis y ocho pasos en función del área portuaria: el puerto principal contaba con seis pasos, mientras que el embarcadero de Sancti Petri, ubicado en el canal que separaba a la isla de tierra firme, tenía ocho pasos ${ }^{29}$. Es innegable que el éxito comercial y marítimo de la ciudad radicaba en el carácter propio de su medio: una bahía con suficiente calado que concedía a todo tipo de embarcaciones refugio de las inclemencias del tiempo.

El acceso al puerto gaditano se realizaba desde el Océano Atlántico a través de la navegación del canal de Sancti Petri o bordeando su contorno costero. Así pues, las zonas de usos portuarios se extendían, a grandes rasgos, por toda la isla, si bien

\footnotetext{
28 A. Debanne (Ed.), Lo Compasso de navegare. Edizione del códice Hamilton 396 con commento linguistico e glossario, Bruselas 2011, 35-36.

${ }^{29}$ Estos datos del portulano de 1296 son prácticamente idénticos a los transmitidos por otros documentos náuticos italianos del siglo XV: ambos coinciden en la profundidad del puerto de Cádiz entre seis y ocho pasos, así como en el ruinoso o deshecho estado de la ciudad. R. González Arévalo, «La costa del reino de Sevilla en la documentación náutica italiana (siglo XV)», Historia de Andalucía. VII Coloquio, Granada 2009, 308-309.
}

«Apud Cadesse»: paisaje marítimo y navegación genovesa en el puerto...» 
específicamente se procedía a cargar o descargar en la extensión de playa defendida por dos espigones - Peña Gorda y San Felipe- en cuyas inmediaciones se hallaban los almacenes destinados a contener las diversas mercancías, dada la función de Cádiz como centro redistribuidor y depósito ${ }^{30}$. De hecho, los navíos de gran porte permanecían fondeados en la propia Bahía a una distancia considerable del litoral con el fin de evitar el encallamiento, posteriormente, se empleaban embarcaciones de menor tamaño para el transporte de las mercancías hasta la ciudad. Así lo manifiesta el propio viaje de la nave «Santa Maria» en 1286 cuando se especifica que a su llegada al puerto de Cádiz los marineros fuesen descargados mediante barcas.

El portulano de 1296 describe a Cádiz como una ciudad devastada. Esta interesante descripción del paisaje urbano responde al carácter fronterizo de este ámbito geográfico. Cabe recordar que el entorno gaditano fue objeto de diversas incursiones provenientes del Norte de África promovidas por los meriníes durante los años setenta y ochenta del siglo XIII. Resulta evidente que estos ataques tuvieron repercusiones negativas en el poblamiento del alfoz gaditano y su desarrollo económico. Pero, ¿hasta qué punto afectó la frontera marítima y terrestre en los intercambios comerciales en el puerto gaditano?

\section{Naves genovesa en Cádiz en el siglo XIII}

La Baja Edad Media se caracterizó por la aparición de dos fenómenos sumamente trascendentes vinculados con el comercio y la navegación: el desplazamiento del tráfico comercial desde el Mediterráneo hacia el Atlántico y la expansión europea hacia nuevos horizontes. El primero de los fenómenos ha sido considerado historiográficamente como una consecuencia directa del avance imparable de los turcos otomanos y a la caída de Acre

30 J. SÁnChez Herrero, Cádiæ. La ciudad medieval y cristiana (1260-1525), Córdoba 1986, 141-143. 
en 1291. La pérdida de control comercial en el Mediterráneo oriental fue compensada, sobre todo para Génova, con la apertura de nuevas rutas marítimas con nuevos mercados de consumo y áreas proveedoras en el Mediterráneo occidental y en el Atlántico norte y medio. Efectivamente, el conocido «repliegue de Oriente hacia Occidente» ${ }^{31}$ favoreció la integración de los centros portuarios atlánticos andaluces dentro de las redes comerciales de las grandes potencias mercantiles europeas ${ }^{32}$.

Los mercaderes genoveses constituyeron una amplia «red de contactos solvente y dinámica» ${ }^{33}$ que les permitió comercializar con absoluta franqueza a lo largo del espacio económico del Mediterráneo tanto oriental como occidental. De hecho, esta comunidad mercantil desarrolló un papel de gran valor estratégico como «catalizadora de procesos de reorientación productiva» ${ }^{34}$. Su forma de actuar respondía al establecimiento de una red de relaciones directas en los puntos económicos más relevantes, es decir, grandes puertos y mercados. Asimismo, desde finales del siglo XIII, los comerciantes genoveses estaban perfectamente establecidos en los principales mercados europeos mediterráneos y atlánticos.

31 J. HeERS, Gênes au XVe siècle: activité économique et problems sociaux, París 1961.

32 Ma. L. ChiApPa MAURI, «Il commercio occidentale di Genova nel XIV secolo», Nuova Rivista Storica 57, 1973, 571-612. G. Pistarino, La capitale del Mediterraneo: Genova nel Medioevo, Génova 1993. P. F. SimbULA, «Apertura de las rutas comerciales de las flotas italianas hacia el Atlántico», A. MALPICA Cuello (Ed.), Navegación marítima del Mediterráneo al Atlántico, Granada 2001, 207-258. A. NiCOLONI, «Commercio maritimo genovese in Inghilterra nel Quattrocento", Atti della Società Ligure di Storia Patria. Nuova Serie XLIII (CXVII), fasc. I, 2007, 215-327. M. BALARD, Gênes et la mer. Genova e il mare, Génova 2017, vol. I/II. R. GonzÁLEZ ArÉvalo, «En el Mediterráneo atlántico: Andalucía y las marinas italianas en la ruta de Poniente (siglo XV)», En Prensa. Agradezco a su autor la consulta del texto inédito.

33 A. FÁbregas García y A. García Porras, «Redes de comercio genovesas en el sur de la Península Ibérica: circulación mercantil y transferencias productivas», Ma. I. DEL Val Valdivieso y P. Martínez Sopena (Dirs.), Castilla y el mundo feudal. Homenaje al profesor Julio Valdeón, Valladolid 2009, 639.

34 A. FÁbregas García y A. García Porras, «Redes de comercio genovesas..., 640.

«Apud Cadesse»: paisaje marítimo y navegación genovesa en el puerto...» 
A pesar de que el centro económico gaditano estuvo precisamente integrado dentro de los circuitos comerciales de la órbita ligur con anterioridad a la conquista castellana, ${ }^{35}$ no fue hasta las últimas décadas del siglo XIII cuando surgió un considerable intercambio mercantil con el sur peninsular. A partir de la década ochenta del siglo XIII, los navíos genoveses anclaron con mayor regularidad en el puerto de Cádiz, coincidiendo con la defensa del Estrecho de Gibraltar y del litoral comprendido entre las desembocaduras de los ríos Guadalquivir y Guadalete con doce galeras a cargo de Benedetto Zaccaria, almirante genovés, quien, a cambio de la protección marítima, recibió la jurisdicción de El Puerto de Santa María y de seis mil doblas de oro anuales ${ }^{36}$. Esta defensa costera, sin lugar a dudas, fomentó el desarrollo de las actividades comerciales y la navegación hacia los centros portuarios andaluces.

La ciudad de Cádiz se instituyó como el puerto del sur peninsular canalizador de las mercancías exportadas desde Génova desde fines del siglo XIII. De hecho, la temprana presencia de naves revela el interés de los mercaderes genoveses por controlar los nuevos mercados y por reorganizar los espacios económicos una vez incorporados al dominio de Castilla. Pero, ¿por qué instauraron su base naval en el puerto gaditano?

Según los planteamientos de Adela Fábregas García y Alberto García Porras, la elección de los comerciantes ligures de

\footnotetext{
35 D. Ríos Toledano, «Cádiz y el comercio marítimo..., 275.

36 R. GonZÁlez ArÉVALO, «Vecinos y propietarios: la integración de los italianos en las sociedades portuarias andaluzas (siglos XIII-XV)», J. A. Solórzano TelecheA, B. Arízaga Bolumburu y M. BochacA (Eds.), Las sociedades portuarias de la Europa atlántica en la Edad Media, La Rioja 2016, 257; «Integración y movilidad social de las naciones italianas en la Corona de Castilla: genoveses, florentinos y venecianos en la Andalucía bajomedieval», L. Tanzini y S. Tognetti (Eds.), Mobilità sociale e forme di integrazione nel tardo Medioevo, Roma 2016, 378-379. J. J. Iglesias Rodríguez, «Micer Benedetto Zaccaria, primer señor de El Puerto, y su tiempo», Monarquía y nobleza señorial en Andalucía. Estudios sobre el señorío de El Puerto (Siglos XIII-XVIII), Sevilla 2003, 35-50.
} 
una determinada área como un «nuevo espacio de penetración» viene concedida «por su interés como base de aprovisionamiento de algún artículo específico, como mercado de consumo de posibilidades de desarrollo óptimo, o bien por la confluencia entre ambas circunstancias, en cuyo caso la zona se presenta como un espacio extraordinario interés» ${ }^{37}$. En esta misma línea, la red portuaria del ámbito de la Bahía de Cádiz reunía ambas condiciones: de un lado, el puerto gaditano fue una importante «base de aprovisionamiento» de las naves que surcaban la ruta de Poniente, durante dicha escala se embarcaban una amplia gama de mercancías específicas: atunes, vinos, mercurio, aceite, grana, así como productos de la Berbería de Poniente y de las islas Canarias; de otro lado, era un mercado de consumo y de redistribución de mercancías orientales, tal como se manifiesta a partir del análisis de las siguientes actas notariales genovesas ${ }^{38}$.

La conquista de las ciudades de Sevilla y Cádiz resultó de vital importancia para la expansión comercial de las marinas de las repúblicas marítimas italianas hacia el Norte de Europa ${ }^{39}$. Ambos puertos se beneficiaron por su carácter intermediario en la ruta de Poniente. Desde el último cuarto del siglo XIII, están constatados los viajes de la marina mercante genovesas hacia Inglaterra y Flandes. Cabe recordar la travesía de Nicolozzo Dugus Spinola en

37 A. FÁbregas García y A. García Porras, «Redes de comercio genovesas..., 644.

38 J. HeErs, Gênes au XVe siècle..., 484. A. NiCOLini, "Commercio marittimo Genovese..., 233. Estas actas notariales ya han sido utilizadas por Raúl González Arévalo para el caso de los puertos nazaríes, R. GonZÁlez ArÉvalo, «Presencias, interacciones y mutaciones italianas en el mar de Alborán (siglos XII-XV). Algunas reflexiones desde la historio-grafía», B. SARR (Ed.), Alborán. Poblamiento e intercambios en las zonas costeras de al-Andalus y el Magreb, Granada 2018, 380 y 382. También fueron referenciadas por George Jehel en su obra culmen sobre los genoveses: G. JEHEL, Les genois en Mediterranee occidentale (fin XI'me - debut XIV ieme siècle). Ebauche d'une stratégie pour un empire, París 1993, 286, 290, 351-352.

39 J. HeErs, «Les hommes d'affaires italiens en Espagne au Moyen Âge: le marché moné-taire», Société et économie à Gênes (XIVe-XVe siècle), Londres 1979, VIII, 75.

«Apud Cadesse»: paisaje marítimo y navegación genovesa en el puerto...» 
$1277^{40}$ o la de las tres galeras de Benedetto Zaccaria, Nicolino Zaccaria y Ughetto Embriaco a Inglaterra cargadas de alumbre de Focea en $1278^{41}$. En este marco cronológico se desarrollaron dos nuevos trayectos: de un lado, la primera ruta puesta en marcha en 1292 unía Focea-Quíos con Flandes-Inglaterra, que supuso la supresión de la estación en Génova, dirigiéndose directamente el navío a Cádiz, única escala antes de afrontar el Océano Atlántico; ${ }^{42}$ y la segunda ruta marítima, de menor rango internacional, enlazaba a Génova con Mallorca y Cádiz, con escalas opcionales en los puertos nazaríes. Ambos trayectos confirman indudablemente el papel del puerto gaditano como eje de las redes comerciales ligures.

En marzo de 1286, Giacomo Lomellino y Beltramino de Mari habían fletado su nave «Santa Maria», anclada en el puerto de Génova, a los hermanos Zaccaria, Benedetto y Manuele ${ }^{43}$. Como revela el contrato de fletamento, el navío debía estar perfectamente acondicionado: «paratam, munitam, furnitam et corredatam», con sus correspondientes instrumentos y materiales: «cum omni sarcia conredo et apparatu ipsius et sufficiente pro dicta navi». La embarcación sería cargada con cualquier tipo de mercancías en Génova durante diez días, allí mismo se enrolarían cuarenta y cinco buenos «marinariis», sobre todo ciudadanos genoveses, contando entre ellos con ocho sirvientes capaces de portar armas. Desde Génova la embarcación navegaría recto

40 R. DOeHAerd, Les relations commerciales entre Gênes, la Belgique et l'Outremont, d'après les archives notariales génoises aux XIIIe et XIVe siècles, Bruselas 1969, vol. III, doc. 1334. P. F. SimbulA, «Apertura de las rutas comerciales..., 211.

${ }^{41}$ R. DOEHAERD, Les relations commerciales entre Gênes..., vol. III, doc. 1356.

42 En 1292, Carlotto y Andalo de Negro, patrones de la coca «San Siro», cargaron alumbre en Focea para después descargarlo en Cádiz y, posteriormente, en Brujas. M. BALARD, Le Roamnie génoise, vol. II, Roma-Génova 1978, 556.

${ }^{43} \mathrm{El}$ apellido Zaccaria aparece escrito en el acta notarial en latín como Iacherie. Resulta probable que se tratara del propio Benedetto Zaccaria, quien llegó a ostentar el título de almirante de Castilla entre 1291-1293 y primer señor de El Puerto de Santa María en 1284. 
hacia Mallorca. En esta ciudad, la tripulación disponía de ocho días de escalas para realizar las labores de carga y descarga de mercancías a la libre voluntad de los fletadores o de sus «noncius» -factores-. Desde la isla de Mallorca el navío navegaría siguiendo la ruta establecida hasta Cádiz. En el puerto gaditano la embarcación podía permanecer fondeada durante ocho o diez días. Así, se estableció que en Cádiz «facere exhonerari per marinarios et cum barchis dicte navis», es decir, los marineros serían desembarcados por medio de barcas, lo que revela que la nave permanecería fondeada en la propia bahía gaditana y los integrantes de la tripulación serían transportados en embarcaciones de menor porte hacia el puerto. Desde el puerto de Cádiz se permitía realizar escalas opcionales en Ceuta, Málaga y/o Almería, siempre y cuando que la nave estuviera bien defendida con «pontibus, ballatoribus, brazolis, falchis, lapidibus, armis et omnibus furnimentis necessariis». Así pues, en el propio contrato de fletamento se establecieron las retribuciones que se deberían ser abonadas en cada puerto: 100 libras genovesas en Génova, 125 en Mallorca y 250 en Cádiz ${ }^{44}$.

Resulta probable que la nave «Santa Maria» no zarpara sola, sino que navegaría en conserva con la embarcación, «Bonaventu-ra», que había arribado a Génova desde Focea, donde se había atisbado en la mencionada nave un cargamento de trescientos cántaros de alumbre propiedad de Giovanni de Rovegno de Castro que había sido adquirido por los hermanos Zaccaria por trescientas libras genovesas. Así pues, la embarcación, fletada por Manuele y Benedetto Zaccaria a Giovanni de Rovegno de Castro, proseguiría su viaje desde Génova hacia Cádiz vía Mallorca. Tal como se había estipulado en el contrato, el cargamento de alumbre podía ser descargado en

44 13-III-1286: E. H. BYrne, Genoese shipping..., doc. XLIII (Génova-Mallorca-CádizCeuta-Málaga-Almería).

«Apud Cadesse»: paisaje marítimo y navegación genovesa en el puerto...» 
Génova o Mallorca sin ningún gasto adicional, en cambio, en el caso de que fuese alijado en Cádiz, los hermanos Zaccaria debían recibir dos sueldos genoveses más por cada cántaro descargado: «salvo quod si defferetur in dicta navi apud Cadesse vel in illis contratis quod dictus Johannes addere debeat et solvere dictis Benedicto et Manuello pro quolibet cantario dicti aluminis occasione nauli soldos duos Janue ultra id quod iam solvit et ita» ${ }^{45}$. Como es bien sabido, el alumbre fue el mineral indispensable para la industria textil, concretamente, para los tintes. La demanda y la distribución de este artículo responde a la creciente manufactura textil castellana de finales del siglo XIII, puesto que se utilizaba en sectores como el curtido y el tinte de las pieles o, bien, como mordiente de los tintes de tejidos de mayor calidad ${ }^{46}$.

En febrero de 1291, los mercaderes Francesco Salamonica y Bartolomeo Calvi fletaron su nave «San Miguel», propiedad de la compañía, a Guilielmo de Vedereto, que se hallaba fondeada en el puerto de Génova. Así, la nave, «bene paratam et munitam marinariis et omni sua sarcia et apparatu sufficientibus et necessariis ad eam», efectuaría el mismo trayecto marítimo que las embarcaciones «Santa Maria»y «Bonaventura». De hecho, la nave disponía de once días para cargar en ella desde veinticinco hasta cuarenta balas y pesos como máximos con mercancías no especificadas en el puerto genovés. El navío zarparía con «ipsas ballas et pondus et nuncios tuos et asnesium» hacia el puerto de Hyères o Mallorca — a la libre voluntad del fletador-, allí podía permanecer fondeado desde cinco hasta ocho días, o en el caso de exceder en días debería desembolsar un pago extraordinario de cincuentas libras genovesas. Desde Hyères o Mallorca la nave

45 22-III-1286: E. H. Byrne, Genoese shipping..., doc. XLV, XLVI, XLVII (FoceaGénova-Mallorca-Cádiz).

46 D. IGUAL Luis, «La producción y el comercio del alumbre en los reinos hispánicos del siglo XV», MEFRM, 126/1, (2014), 261. 
navegaría hasta el puerto gaditano, en el que podría permanecer anclada durante quince días y cobrar por cada bala y cada peso doce maravedíes de Sevilla, tal como se especifica en el propio contrato de fletamento: «dare et solvere in Cadese pro naulo cuiuslibet balle et pondi predictarum Marabotinos duodecim de Sybilia infra dies quindecim postquam dicta navis alluc applicuerit» ${ }^{47}$.

En contraposición a los planteamientos esgrimidos por Manuel González Jiménez que se centraron en ratificar el estado de abandono y el expolio de la ciudad gaditana, así como la exclusión de su puerto dentro de las redes comerciales a finales del siglo XIII, ${ }^{48}$ los protocolos notariales genoveses vislumbran una imagen absolutamente opuesta. Efectivamente, el puerto de Cádiz participó en el comercio genovés desde las dos últimas décadas del siglo XIII. De hecho, su mercado ofrecía a los mercaderes ligures una notable rentabilidad a tenor de la demanda de mercancías orientales, sobre todo alumbre de Focea. Cabe recordar que el alumbre de Giovanni de Rovegno descargado en Cádiz sería vendido a un precio superior, en oposición a si fuera comerciado en Génova o Mallorca, como quedó estipulado en el contrato $^{49}$.

De tal modo, la arribada de estas naves genovesas al puerto gaditano se debe interpretar como una consecuencia inmediata a la política de concesión de franquicias fiscales promovida por los reyes castellanos para impulsar el desarrollo de

47 28-II-1291: E. H. BYrne, Genoese shipping..., doc. LIV (Génova-Hyères-MallorcaCádiz).

48 M. GonZÁLEZ JiMÉNEZ, «Cádiz frente al mar: de los proyectos alfonsíes al Privilegio de 1493», Estudios de Historia y de Arqueología Medievales X, (1994), 92-94. De hecho, Manuel González Jiménez afirmó que «Cádiz se hundió en una larga fase de atonía económica y decadencia demográfica de la que comenzaría a recuperarse al final de la Edad Media», citado en M. GonZÁLEZ JIMÉNEZ, «Cádiz en el siglo XIII..., 757.

49 22-III-1286: E. H. ByRne, Genoese shipping..., doc. XLV.

«Apud Cadesse»: paisaje marítimo y navegación genovesa en el puerto...» 
los intercambios mercantiles. La ciudad de Cádiz disfrutaba de un privilegio real concedido por Alfonso X —en 1284 confirmado por Sancho IV - que autorizaba a los comerciantes extranjeros a pagar un tercio menos de los derechos que debían abonar en Sevilla en el caso de que descargasen en su puerto ${ }^{50}$.

\begin{tabular}{|c|c|c|c|c|}
\hline Año & Nave & Escalas & Carga & Duración (Días) \\
\hline 1286 & Santa Maria & $\begin{array}{c}\text { Génova-Mallorca- } \\
\text { Cádiz-Ceuta-Málaga- } \\
\text { Almería }\end{array}$ & - & $\begin{array}{c}\text { Génova: } 10 \\
\text { Mallorca: } 8 \\
\text { Cádiz: } 8-10 \\
\text { Ceuta: } 2 \\
\text { Málaga: } 2 \\
\text { Almería: } 2 \\
\end{array}$ \\
\hline 1286 & Bonaventura & $\begin{array}{l}\text { Focea-Génova- } \\
\text { Mallorca-Cádiz }\end{array}$ & $\begin{array}{c}\text { Alumbre: } \\
2 \text { sueldos por } \\
\text { cántaro en Cádiz }\end{array}$ & - \\
\hline 1291 & San Miguel & $\begin{array}{l}\text { Génova-Hyères- } \\
\text { Mallorca-Cádiz }\end{array}$ & $\begin{array}{c}\text { 25-40 Balas: } \\
12 \text { mrs. por } \\
\text { cántaro en Cádiz }\end{array}$ & $\begin{array}{l}\text { Génova: } 11 \\
\text { Hyères: } 5-8 \\
\text { Mallorca: } 5-8 \\
\text { Cádiz: } 15\end{array}$ \\
\hline 1292 & San Siro & Focea-Cádiz-Brujas & Alumbre & - \\
\hline
\end{tabular}

Tabla 2. Naves genovesas en Cádiz en el siglo XIII

La ciudad de Cádiz presentaba un enorme atractivo para los mercaderes ligures. Las actas notariales genovesas manifiestan una participación activa del puerto gaditano en el comercio mediterráneo. A pesar de la imagen negativa que perfila el portulano de 1296 sobre la ciudad gaditana, no parece que tuvieran gran efecto en el desarrollo mercantil de su puerto como revelan los contratos analizados. En este sentido, cabe preguntarse si la ciudad de Cádiz parecía más bien «un emporio comercial que un centro urbano», tal como planteó Antonio Collantes de Terán ${ }^{51}$.

50 «Otorgábales otrosí, que todo mercadero estraño que hi viniese con mercaduría, que diese el tercio menos de los derechos que hobiese á dar segun dan en Sevilla». M. GonZÁlez JimÉneZ, Diplomatario Andaluz de Alfonso X..., nº 534.

51 A. Collantes de Terán SÁnCHEZ, «Las ciudades de Andalucía desde el siglo XIII a comienzos del siglo XV», Una gran ciudad bajomedieval: Sevilla, Sevilla 2008, 252. 
Paralelamente al desarrollo de estos notables intercambios comerciales, desde el último cuarto del siglo XIII se afianzaron comunidades genovesas en las principales ciudades andaluzas, con Sevilla a la cabeza ${ }^{52}$. De hecho, esta comunidad mercantil fue capaz de desarrollar una gran capacidad de integración en los diversos núcleos urbanos de la Bahía de Cádiz. Una de las estrategias más aplicadas para alcanzar la promoción social fue la adquisición de propiedades urbanas y rurales con el fin de obtener la vecindad ${ }^{53}$. A modo de ejemplo, en 1293, miçer Bonavía de Vivaldo compró en El Puerto de Santa María a Domingo Serrano y su mujer, doña Matea, treinta aranzadas de tierra de cereal en las Salinas por la cantidad de setenta maravedíes ${ }^{54}$. De hecho, había llegado a ocupar el cargo de alcaide de El Puerto de Santa María y a concentrar más propiedades en el entorno: en 1302, adquirió dieciséis caballerías en Grañina por compra que procedió a Simón Pérez y a su mujer, doña Sancha, vecinos de El Puerto, por el valor de 950 maravedíes; y, en 1305, amplió sus posesiones en las Salinas con la compra de treinta aranzadas por 120 maravedíes a Garci Pérez Soriano, su mujer, María Muñoz, y Pascual, su hijo, vecinos de Jerez ${ }^{55}$.

No obstante, como ha señalado Raúl González Arévalo, la presencia de mercaderes extranjeros en Cádiz y su bahía se puede constatar con anterioridad gracias a la carta otorgada por Alfonso X a El Puerto de Santa María en 1280, dirigida a:

\footnotetext{
52 R. GONZÁlez ArÉVAlO, «Vecinos y propietarios..., 251-257.

53 R. GonzÁlez Arévalo, «Vecinos y propietarios..., 249-284. M. Á. Ladero QUESADA, «Los genoveses en Sevilla y su región (siglos XIII-XVI): Elementos de permanencia y arraigo», Los mudéjares de Castilla y otros estudios de Historia Medieval Andaluza, Granada 1989, 301.

54 J. E. Jiménez López de Eguileta, «Orígenes de la institución notarial en el Puerto de Santa María (siglos XIII y XIV)», Revista de Historia de El Puerto 59 (2 Semestre), (2017), 18-20.

55 J. E. Jiménez López de Eguileta, «Micer Bonavía de Vivaldo, alcaide de El Puerto de Santa María, y los orígenes del latifundismo en la Baja Andalucía (siglos XIII y

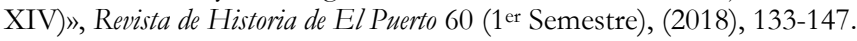

«Apud Cadesse»: paisaje marítimo y navegación genovesa en el puerto...» 
Todos los castellanos e leoneses e vaioneses o portugueses e a todos los del sennorio del rey de Françia e del rey de Anglaterra e del rey de Aragón e a los de Marsella e o todo el otro sennorio del rey de Charles e a los de Benosa e de Pisa e de Venecia ${ }^{56}$.

\section{Conclusiones}

Es innegable que las fuentes genovesas contribuyen a paliar el vacío documental castellano de época bajomedieval, como bien sucede con la ciudad de Cádiz, cuya carencia archivística ha sido denunciada en innumerables ocasiones por los investigadores que se han aproximado a reconstruir su pasado medieval. A partir del análisis de estas actas notariales hemos pretendido arrojar luz sobre el papel mercantil del puerto gaditano durante la Baja Edad Media.

A pesar de las múltiples vicisitudes originadas a tenor de la proximidad a la frontera marítima con el mundo islámico, la ciudad gaditana participó activamente en el comercio internacional desde finales del siglo XIII. Cádiz fue uno de los puertos castellanos receptores de mercancías exportadas por vía marítima por los mercaderes ligures. Ejerció como fondeadero rector en las redes mercantiles de la República de Génova en el célebre «Mediterráneo atlántico». Su preponderancia naval y portuaria quedó plasmada con evidencia en la navegación y el comercio.

De hecho, la ciudad de Cádiz merece un estudio detallado y exhaustivo sobre su puerto, sus instalaciones portuarias, sus actividades económicas, su intervención en las redes comerciales internacionales y regionales, su relevancia en las rutas atlánticas y mediterráneas, así como sobre los diversos mercaderes y

\footnotetext{
56 A. Ballesteros, Sevilla en el siglo XIII, Madrid 1913, Apéndice C, CCLXXX. Citado en R. GonZÁLEZ ArÉvalo, «Vecinos y propietarios..., 254.
} 


\section{RÍos TOLEDANO}

marineros que la convirtieron en una de las principales ciudades portuarias de la Europa occidental. Un estudio exhaustivo que abarque desde las fuentes archivísticas —más allá de las meramente castellanas - hasta las iconográficas, cartográficas, cronísticas o arqueológicas. En este marco cabe recordar las palabras de Roberto Sabatino Lopez: Cádiz «was visited by many Genoese merchants, but there is no monograph on its trade in the Middle Ages».

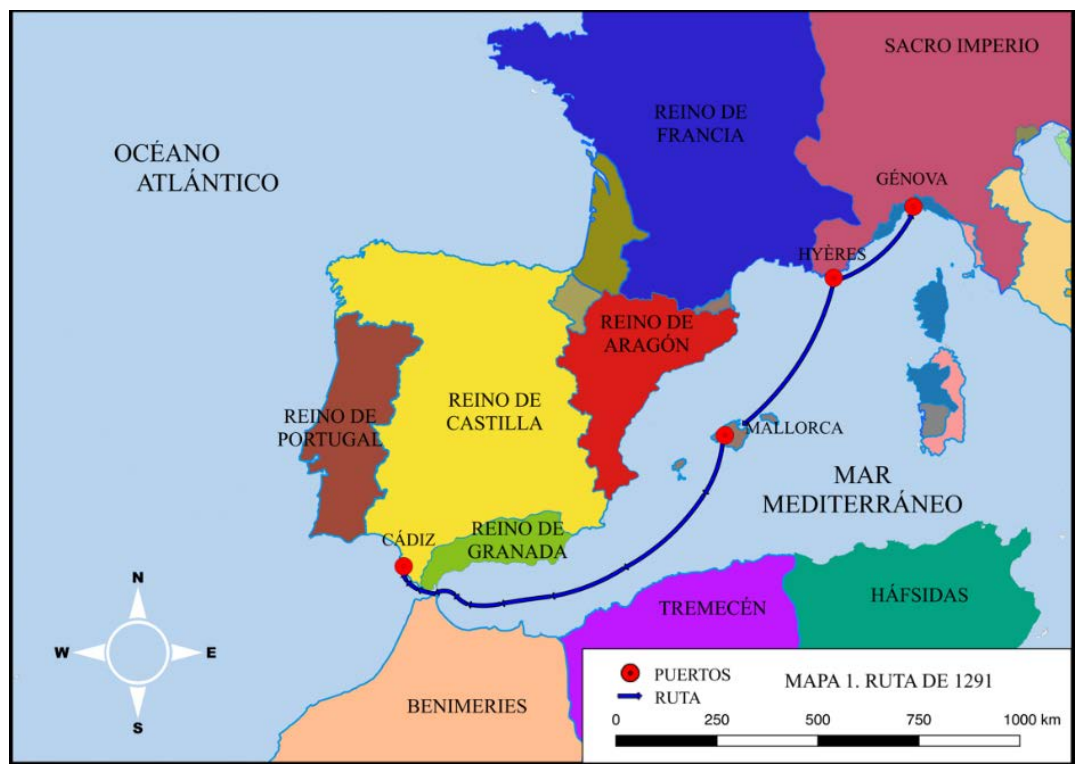

Mapa 1. Ruta de 1291 (CDaniel Ríos Toledano)

«Apud Cadesse»: paisaje marítimo y navegación genovesa en el puerto...» 


\section{Bibliografía}

E. Aznar VAllejo, «Experiencia marítima: las rutas y los hombres del mar», A. COllantes de Terán SÁNCHEZ y A. García-BAQUero GonZÁlez(Coords.), Andalucía 1492: raz̧ones de un protagonismo, Sevilla 1992, 123-156.

M. BALARD, Le Roamnie génoise, Roma-Génova 1978, vol. I/II.

M. BALARD, Gênes et la mer. Genova e il mare, Génova 2017, vol. I/II.

A. BALLESTEROS, Sevilla en el siglo XIII, Madrid 1913.

J. M. BeLlo LeÓN, «El Reino de Sevilla en el comercio exterior castellano (siglos XIV-XV)», H. CASADO AlONSO (Ed.), Castilla y Europa: comercio y mercaderes en los siglos XIV, XV y XVI, Burgos 1995, 57-80.

E. H. BYRne, Genoese shipping in the twelfth and thirteenth centuries, Cambridge 1930.

L. Charlo Brea y M. B. Piqueras García, «Bulas fundacionales de la Diócesis de Cádiz», Actas do IV Congresso Internacional de Latim Medieval Hispánico, Lisboa 2006, 333-344.

$\mathrm{M}^{2}$. L. CHIAPPA MAURI, «Il commercio occidentale di Genova nel XIV secolo», Nuova Rivista Storica 57, 1973, 571-612.

A. Collantes de Terán SÁNCHeZ, «Las ciudades de Andalucía desde el siglo XIII a comienzos del siglo XV», Una gran ciudad bajomedieval: Sevilla, Sevilla 2008, 225-262.

A. Collantes de Terán SÁnchez, «Papel del Atlántico en la configuración de Andalucía», Historia. Instituciones. Documentos, 35, (2008), 85-105.

G. Costamagna, Corso di scritture notarili medievali genovesi, Génova 2017.

A. Debanne (Ed.), Lo Compasso de navegare. Edirione del códice Hamilton 396 con commento linguistico e glossario, Bruselas 2011.

D. Ríos Toledano, «Apud Cadesse»: Paisaje marítimo y navegación genovesa en el puerto de Cádiz en el siglo XIII», Suplemento RIPARIA 2 (2019), 81-111. 
R. DOEHAERD (Ed.), Les relations commerciales entre Gênes, la Belgique et l'Outremont, d'après les archives notariales génoises aux XIII et XIV siècles, Bruselas 1969.

A. FÁbregas García y A. García Porras, «Redes de comercio genovesas en el sur de la Península Ibérica: circulación mercantil y transferencias productivas», $\mathrm{M}^{2}$. I. DEL VAL VALDIVIESO y P. MARTínez SOPENA (Dirs.), Castilla y el mundo feudal. Homenaje al profesor Julio Valdeón, Valladolid 2009, 639-655.

A. Franco Silva, La Isla de León en la Baja Edad Media, San Fernando 1995.

R. GonzÁlez Arévalo, «La costa del reino de Sevilla en la documentación náutica italiana (siglo XV)», Historia de Andalucía. VII Coloquio, Granada 2009, 301-317.

R. GONZÁLEZ ARÉVALO, «Vecinos y propietarios: la integración de los italianos en las sociedades portuarias andaluzas (siglos XIII-XV)», J. A. SOlórzano TelecheA, B. Arízaga BOlumburu y M. BOCHACA (Eds.), Las sociedades portuarias de la Europa atlántica en la Edad Media, La Rioja 2016, 249-284.

R. GONZÁlEZ ARÉVALO, «Integración y movilidad social de las naciones italianas en la Corona de Castilla: genoveses, florentinos y venecianos en la Andalucía bajomedieval», L. Tanzini y S. Tognetti (Eds.), Mobilità sociale e forme di integrazione nel tardo Medioevo, Roma 2016, 375-401.

R. GONZÁlEZ ARÉVALO, «Presencias, interacciones y mutaciones italianas en el mar de Alborán (siglos XII-XV). Algunas reflexiones desde la historiografía», B. SARR (Ed.), Alborán. Poblamiento e intercambios en las zonas costeras de al-Andalus y el Magreb, Granada 2018, 361-410.

R. GonzÁlez ArÉvalo, «En el Mediterráneo atlántico: Andalucía y las marinas italianas en la ruta de Poniente (siglo XV)», En Prensa.

M. GonZÁlez JimÉnez (Ed.), Diplomatario Andaluz de Alfonso X, Sevilla 1991.

«Apud Cadesse»: paisaje marítimo y navegación genovesa en el puerto...» 
M. GONZÁLEZ JiMÉNEZ, «Cádiz frente al mar: de los proyectos alfonsíes al Privilegio de 1493», Estudios de Historia y de Arqueología Medievales X, (1994), 83-99.

M. GONZÁLEZ JIMÉNEZ, «La idea y la práctica de la Cruzada en la España medieval: Las Cruzadas de Alfonso X», El Mediterráneo: hechos de relevancia histórico-militar y sus repercusiones en España, Sevilla 1997, 171-186.

M. GonzÁlez Jiménez (Ed.), Repartimiento de El Puerto de Santa María, Sevilla-El Puerto de Santa María 2002.

M. GonZÁlez JimÉNEZ, "Cádiz en el siglo XIII: Historia de un Proyecto frustrado», M. GONZÁLEZ JimÉNEZ y I. MONTES Romero-CAMACHO (Coords.), La Península Ibérica entre el Mediterráneo y el Atlántico. Siglos XIII-XV, Cádiz-Sevilla 2006, 747758.

J. HEERS, Gênes au XVe siècle: activité économique et problems sociaux, París 1961.

J. HEERs, «Les hommes d'affaires italiens en Espagne au Moyen

Âge: le marché monétaire», Société et économie à Gênes (XIV $V^{\circledR} X V^{\circledR}$ siècle), Londres 1979, VIII, 74-83.

A. DE HorozCO, Historia de Cádir, edición, introducción y notas a cargo de A. Morgado García, Cádiz 2001.

J. J. Iglesias RodrígueZ, «Micer Benedetto Zaccaria, primer señor de El Puerto, y su tiempo», Monarquía y nobleza señorial en Andalucía. Estudios sobre el señorío de El Puerto (Siglos XIII-XVIII), Sevilla 2003, 35-50.

D. IGUAL LUIS, «La producción y el comercio del alumbre en los reinos hispánicos del siglo XV», MEFRM, 126/1, (2014), 259276.

G. JEHEL, Les genois en Mediterranee occidentale (fin XI ${ }^{\text {ime }}$ - debut XIV ${ }^{\text {ime }}$ siècle). Ebauche d'une stratégie pour un empire, París 1993.

J. F. JimÉNEZ ALCÁZAR, «Castilla y el mar Mediterráneo: encuentros y desencuentros en la Baja Edad Media», Intus-Legere Historia, vol. 5, 2, (2011), 7-33. 
J. E. JimÉnez López de EguiLETA, «Orígenes de la institución notarial en el Puerto de Santa María (siglos XIII y XIV)», Revista de Historia de El Puerto 59 (2 Semestre), (2017), 9-22.

J. E. JimÉnEz López DE EGuILETA, «Micer Bonavía de Vivaldo, alcaide de El Puerto de Santa María, y los orígenes del latifundismo en la Baja Andalucía (siglos XIII y XIV)», Revista de Historia de El Puerto 60 (1 ${ }^{\text {er }}$ Semestre), (2018), 133-147.

J. E. JimÉNEZ López DE EGUiLETA, «Las tierras de las Salinas de El Puerto de Santa María, el repartimiento y término de Sidueña y la jurisdicción de Cádiz a finales del siglo XIII», En prensa.

M. Á. LAdero Quesada y M. GonzÁlez Jiménez, «La población en la frontera de Gibraltar y el repartimiento de Vejer (siglos XIII y XIV)» Historia. Instituciones. Documentos, 4, (1977), 199-316.

M. Á. LADERO QUESADA, «Los genoveses en Sevilla y su región (siglos XIII-XVI): Elementos de permanencia y arraigo», Los mudéjares de Castilla y otros estudios de Historia Medieval Andaluza, Granada 1989, 283-312.

E. MARTÍN GUTIÉRREZ, «El aprovechamiento de humedales y marismas en el término de Cádiz: segunda mitad del siglo XIII», Qui lacus aquae stagna paludes sunt... Estudios históricos sobre humedales en la Bética, L. G. Lagóstena Barrios (Ed.), Cádiz 2015, 121-147.

C. Miguel y VigiL, Colección Histórico-Diplomático del Ayuntamiento de Oviedo, Oviedo 1889.

A. NiCOLONI, "Commercio maritimo genovese in Inghilterra nel Quattrocento», Atti della Società Ligure di Storia Patria. Nuova Serie XLIII (CXVII), fasc. I, 2007, 215-327.

G. Pistarino, La capitale del Mediterraneo: Genova nel Medioevo, Génova 1993.

D. Ríos TOLEDANO, «Cádiz y el comercio marítimo genovés en el siglo XIV», Medievalismo 28, (2018), 271-293.

D. Ríos Toledano, «El puerto de Cádiz en la Baja Edad Media: una introducción a su estudio», En Prensa.

«Apud Cadesse»: paisaje marítimo y navegación genovesa en el puerto...» 
D. Ríos Toledano, «En el Atlántico musulmán: rutas, intercambios y saqueos en Cádiz», En prensa.

C. Rosell (Ed.), Crónicas de los reyes de Castilla desde Don Alfonso El Sabio hasta los católicos Don Fernando y Doña Isabel, vol. I, Madrid 1875.

J. I. Ruiz DE LA PEÑA SOLAR, «Las villas castellanas de la costa cántabro-atlántica y su proyección comercial en el Mediterráneo occidental», Revista d'historia medieval, 11, 2000, 41-66.

J. SÁNCHEz HeRrero, Cádiz. La ciudad medieval y cristiana (12601525), Córdoba 1986.

R. SÁnCHEz SAUS, "Cádiz y Alfonso X el Sabio. Traslado de la sede asidonense a Cádiz. Repoblación de la ciudad y su término durante su reinado», Traslatio Sedis: catálogo de la exposición conmemorativa del 750 aniversario del traslado de la sede episcopal a Cádir, Granada 2018, 66-102.

H. SANCHO DE SOPRANIS, «La repoblación y el repartimiento de Cádiz por Alfonso X», Hispania, 15, (1955), pp. 483-539.

P. F. Simbula, «Apertura de las rutas comerciales de las flotas italianas hacia el Atlántico», A. MALPICA CUELlo (Ed.), Navegación marítima del Mediterráneo al Atlántico, Granada 2001, 207-258. 